\title{
LA NATURALEZA HUMANA, FUNDAMENTO DE LA EDUCACIÓN
}

Dra. Ana Teresa López de Llergo

Sumario: Introducción. 1.Concepto de naturaleza. 2.La persona humana. 3.La concreción de la naturaleza humana en cada persona. 4.Las potencias humanas y sus operaciones. 5.La educación de la persona humana. Conclusiones: sobre el quehacer del pedagogo. Glosario. Bibliografía. Esquemas.

\section{INTRODUCCIÓN}

EL CAMBIO DE MILENIO PUEDE Y DEBE SERVIRNOS PARA HACER UNA PROFUNDA revisión de los fundamentos educativos y de su impacto en la construcción de la cultura a lo largo de los siglos. El binomio educación-cultura es importante porque la cultura es causa, contenido y efecto de la educación. Es natural, entonces, que nos veamos comprometidos, desde el punto de vista pedagógico, a revisar el sistema educativo y su fundamento antropológico: la naturaleza humana. Este análisis ha de ayudarnos a descubrir lo que varía y lo que es constante en el proceso educativo. Lo invariable es el ser humano. Al parecer este aspecto tan obvio se ha obscurecido por ciertas posturas antropológicas reduccionistas, pues han relegado el acervo metafísico.

La educación es un proceso de perfeccionamiento de lo específicamente humano ${ }^{1}$. Pero lo específico de la persona no se da en abstracto, se concreta en cada uno de nosotros. Así, la naturaleza humana -común a todos- es el punto de partida para un proceso educativo siempre personal e inédito.

El objetivo de este estudio es ayudar a que los educadores reflexionen sobre la naturaleza humana, considerada como el sustrato del proceso educativo. Cuando se conocen las posibili- 
dades de la naturaleza humana, es más fácil coadyuvar en la maravillosa tarea que cada uno tiene, de alcanzar el matiz singular de perfección que puede darse en su persona.

La tarea de un buen educador, por tanto, está circunscrita a lo que realmente es la condición humana. No podrá educar bien quien parte de hipótesis inadecuadas o planteamientos meramente empíricos sobre la persona y su finalidad. Por eso, para tener un acercamiento a cada persona en concreto, hay que redescubrir el concepto de naturaleza y aplicarlo al concepto de ser humano.

\section{CONCEPTO DE NATURALEZA}

Estamos muy acostumbrados a encerrarnos en el concepto moderno de naturaleza, según la cual, ésta no vendría a ser más que un conjunto de leyes de regularidad matemática. Una vez que este enfoque ha demostrado su insuficiencia, por tanto, conviene recordar que el concepto de naturaleza humana posee una riqueza que no debe reducirse por prejuicios ideológicos.

La palabra naturaleza proviene de la raíz latina gena que significa engendrar. De esta raíz se origina la palabra natura, derivada del verbo nascor, cuyo significado es nacer. En la lengua griega, lo correspondiente a natura es la palabra phisis, emparentada con el verbo phyo que significa producir, crecer, hacer y que a su vez encierra la idea de nacer por sí mismo. La raíz común de esta familia de palabras griegas es el término bhú, que se relaciona con el verbo ser. ${ }^{2}$

En lo profundo del término naturaleza se encuentran, por un lado, las ideas de nacimiento y de generación y, por el otro, las de ser y devenir. La naturaleza tiene el vigor de producir otros vivientes que conservan las mismas características esenciales del ser que los origina y la capacidad de realizar las operaciones que le son propias.

El sustrato permanente de todo sujeto es la naturaleza, coprincipio con el acto de ser de tal sujeto. Además, circunscribe 
las operaciones que cada cual puede realizar.

Como principio del sujeto la naturaleza es:

* Causa material y se comporta como principio pasivo. Delimita a cada uno.

* Causa formal y se comporta como principio potencial activo porque señala el modo al ser.

Como principio de las operaciones la naturaleza es:

* Causa eficiente porque es la esencia en la dimensión predictiva de la actualización de las potencialidades, indica cómo se pueden desplegar las posibilidades de acuerdo con la naturaleza de cada ser.

* Causa final puesto que es el orden que la esencia presupone para que se realicen las operaciones. Esto tiene que ver con la dimensión ética de las acciones humanas.

Lo natural en el ser humano tiene carácter de fin porque señala lo que hay que alcanzar: la propia perfección. ${ }^{3}$ Pero el fin se alcanza con el ejercicio de la libertad, por tanto, lo propio de la persona es su capacidad para lograr el fin. De ahí que la naturaleza humana es autotrascendencia: apertura, actividad y posesión de aquellos fines que le son propios ${ }^{4}$.

El conocimiento de la naturaleza de alguien es mediato, lo inmediato es observar las operaciones. Cuando relacionamos estas últimas con la naturaleza, podemos integrar diversos individuos dentro de una misma especie.

\section{LA PERSONA HUMANA}

La persona humana existe en cada varón y en cada mujer. Cuando hablamos de hombre incluimos a ambos, ya que, en lo esencial, los dos abarcan todo lo que comprende la naturaleza humana. Después de su nacimiento, la persona continúa con más fuerza e independencia un proceso de individualización que ya se daba en el seno materno, aunque de una manera muy 
dependiente.

Pero el hombre -por su condición de criatura- no elige su naturaleza, la recibe de su Creador. Es una naturaleza con grandes posibilidades, que se puede actualizar a lo largo de la vida y que, en la medida en que se despliegue hacia la perfección, conquista la felicidad que es la satisfacción que se produce al ir actualizando bien la naturaleza. Además "el hombre es mortal, el hombre es sujeto (persona). El único que puede decir *soy mortal y soy persona* es el hombre. El animal vive y deja de vivir, pero no puede decir soy ". 5

La realidad de la muerte, claramente comprobada, nos permite afirmar que el ser humano es un compuesto de alma y cuerpo; si no, no moriría. Pero, aunque compuesto, es uno, un único sujeto. La parte corpórea es semejante a la del animal y por eso se descompone, pero cuando está vivificada por el alma espiritual ${ }^{6}$ participa de esta dimensión. Además, el ser humano por su espiritualidad, puede volverse sobre sí, saber que existe y darle un sentido a su vida y a su muerte. Abrirse a los demás, conocerlos, respetarlos y amarlos.

La persona tiene responsabilidad personal y social en el despliegue de la propia naturaleza, como proceso de autoperfeccionamiento, y también en el de los demás, a través de la ayuda educativa que pueda brindarles. Esa responsabilidad se asume en cada momento de la existencia, en cada instante de la vida. Así el tiempo se convierte en un tesoro, pues sólo en él se actualizan y se concretan las múltiples posibilidades de la naturaleza humana. Se hace mal uso de tal tesoro cuando no se aprovecha para el perfeccionamiento propio y ajeno, por eso, la educación ha de promover el mejor modo de usar el tiempo.

Cada persona concreta la naturaleza humana en un ser singular, que se reconoce por su nombre propio y, también, por el modo como realiza las operaciones comunes a su especie. Así, el papel que desempeña entre los miembros de la sociedad, es 
único e irrepetible, sin dejar de ser semejante al de los demás.

La noción de persona va ligada indisociablemente al nombre, que se adquiere o se recibe después del nacimiento de parte de una estirpe que, junto con otras, constituye una sociedad, y en virtud del cual el que lo recibe queda reconocido y facultado con unas capacidades (papeles o roles que puede desempeñar), es decir, queda constituido como actor en un escenario -la sociedad-, de forma que puede representar o ejercer las funciones o capacidades que le son propias en el ámbito de la sociedad. ${ }^{7}$

\section{LA CONCRECIÓN DE LA NATURALEZA HUMANA EN CADA PERSONA}

El concepto de naturaleza del hombre se encarna y se hace realidad en cada persona, a través de una vida espiritual típicamente humana. Esta espiritualidad comprende potencias y operaciones que se concretan en un determinado modo de vivir.

El principio vital de todo ser viviente es el alma, y, en el hombre, es el fundamento de la vida psíquica. El alma humana es, entonces, un principio de vida espiritual cuyo origen no depende del cuerpo al que vivifica, pero que, por la unidad substancial, necesita de él para manifestarse y para perfeccionarse. Aunque el hombre realiza funciones vitales inferiores, vegetativas y sensitivas, que dependen del aspecto neurofísiológico; por su unidad substancial y porque lo superior comprende a lo inferior, el espíritu humano impregna todas las operaciones vitales. Por eso, el psiquismo del hombre es espiritual.

En el ser humano las operaciones vitales tienen características distintas de las operaciones propias de los animales, que sólo dependen de lo meramente corpóreo. La persona es capaz de reflexionar sobre sí misma, de dar intencionalidad a sus acciones y de buscar, a través de ellas, la satisfacción de sus necesidades materiales y espirituales. De aquí la riqueza y com- 
plejidad de las operaciones humanas: el hombre se alimenta como hombre, siente como hombre, descansa como tal, etcétera.

\section{LAS POTENCIAS HUMANAS Y SUS OPERACIONES}

Potencia es aquello que puede ser, pero que aún no es. La realidad de la potencia se conoce cuando ese poder se actualiza en las operaciones del sujeto. Por ejemplo, el aprendizaje se manifiesta en nuestra capacidad de resolver problemas concretos ${ }^{8}$.

El hombre tiene potencias vegetativas que reconocemos cuando se nutre, crece y se reproduce. Mediante la reproducción es posible la existencia de otros seres de su misma naturaleza, pero, al mismo tiempo, únicos e irrepetibles. Tiene también potencias sensitivas que reconocemos cuando actualiza sus sentidos externos y vive las sensaciones auditivas, tactiles, etcétera, o cuando actualiza sus sentidos internos y realiza percepciones, imaginaciones, memorizaciones o premoniciones. Pero lo más digno del hombre se encuentra en sus potencias espirituales: la inteligencia y la voluntad, entre cuyas operaciones se encuentran el pensar, gracias a la inteligencia, y decidir y querer, por la voluntad.

La inteligencia se actualiza con el conocimiento racional. Podríamos decir que la racionalidad es el acto más complejo de la inteligencia, de modo semejante a como decimos que la percepción es el acto del primer sentido interno, el sentido común. La inteligencia se apoya tanto en los datos que le aportan los sentidos o psiquismo sensitivo, como en el proceso neurofisiológico que desencadenan en el cerebro los datos recibidos por los sentidos. A su vez, la inteligencia se expresa utilizando el proceso neurofisiológico. Si éste queda dañado, la manifestación del proceso intelectivo queda enmascarada. Por ejemplo, cuando hay una parálisis cerebral la persona no puede hablar bien aunque sus ideas sean coherentes.

La voluntad es la potencia espiritual que se actualiza con la 
volición o acto del querer. Este acto se conoce, precisamente, por el movimiento que realiza la persona para conseguir aquello que quiere. La libertad es característica de la voluntad, es la manifestación más alta del obrar humano, porque gracias a ella la persona es capaz de elegir por sí misma.

Siempre que el hombre se mueve hacia algo, hay un diálogo previo entre la potencia cognoscitiva (inteligencia) y la apetitiva (voluntad). La primera presenta datos, y la segunda elige de entre ellos, o no elige. El hombre es, entonces capaz de conocer y apetecer, y esta capacidad puede realizarla en el nivel sensitivo y en el espiritual, por su condición corpóreo-espiritual.

En el nivel del conocimiento sensible se desencadenan las pasiones, como actos propios del apetito sensitivo. Las pasiones se subdividen en dos grupos: las concupiscibles, cuyo objetivo es alcanzar bienes accesibles a las personas o evadir con facilidad males cercanos, y las irascibles donde los bienes por alcanzar o los males por evitar, requieren de mucho esfuerzo. En el nivel espiritual, el conocimiento racional desencadena las voliciones, como actos propios del apetito intelectual.

Por lo tanto el hombre, como el animal, tiene pasiones apetitos sensibles-, pero en el ser humano estas pasiones se humanizan gracias al apetito intelectual que genera los afectos, cuya gama es compleja y variadísima. Por ejemplo, aunque el instinto sexual aparece tanto en los animales como en los seres humanos, en estos últimos, la sexualidad puede y debe vivirse en un contexto que respete toda la dignidad y riqueza propia de los seres personales. Lo mismo sucede con el hambre, en donde la persona, para satisfacerla ha creado la gastronomía y ha humanizado el proceso.

Ya sabemos que el ser humano es irreductible a fórmulas matemáticas o a esquemas empobrecedores. Con un propósito meramente didáctico podemos intentar una descripción de la integridad de la naturaleza humana, con el auxilio de dos es- 


\section{quemas.}

En el esquema número 1 se presentan el ámbito cognitivo y el apetitivo de la persona humana, cada uno en sus dos dimensiones, sensitiva y espiritual. La complejidad de la actuación humana se debe a que cuando se inicia el conocimiento sensible por el ejercicio de los sentidos externos e internos se desencadenan dos operaciones: la del conocimiento intelectual y la de los apetitos sensitivos. A su vez, el apetito volitivo se estimula por la influencia del conocimiento intelectual y también por la presión que ejercen las pasiones. Siempre existe la posibilidad de un predominio pasional, si lo espiritual pierde su carácter directivo.

La educación ha de lograr que la voluntad ejerza su señorío en el ámbito apetitivo, y que las pasiones se subordinen a la voluntad, siempre que ésta haya sido debidamente informada por la inteligencia. Así el hombre tendrá una conducta acorde con su condición de persona.

En la parte inferior del esquema número 1 aparece la afectividad, palabra que etimológicamente proviene del vocablo latino affecto: querer asir o agarrar ${ }^{9}$. La afectividad está concebida como una realidad psíquica con entidad propia que impregna a toda la vida sensitiva y espiritual. Por lo general se manifiesta con respuestas inmediatas de agrado o desagrado ante algunos estímulos, y respectivamente provoca las reacciones de acercamiento o huida, la primera actitud desencadenará la entrega y el espíritu de servicio; la segunda, el enquistamiento y el egoísmo. Por eso la afectividad influye en las relaciones (por ejemplo con la inteligencia) y que repercuten en la conducta externa. De manera que la entrega presenta variadísimos matices que van desde la comprensión hasta la propia donación. El espíritu de servicio aparece, entre otras actitudes, como abnegación o promoción de actividades grupales.

La afectividad en el ser humano engloba las pasiones - emociones y sentimientos - coloreadas por la espiritualidad, por 
eso, la frontera de la afectividad es imprecisa y a veces parece desplazarse más a lo sensitivo.

A partir de la afectividad se establecen las relaciones humanas y los lazos que unen a las personas con el medio, por eso, la expresión afectiva es imprescindible en el desarrollo psicológico normal de cada uno. El pedagogo ha de promover el equilibrio y el bienestar afectivo. Por ello, la educación integral deberá considerar los dos ámbitos, el sensitivo-espiritual y el cognitivo-apetitivo, con el fin de lograr un equilibrio que, sin descuidar la afectividad, potencie la inteligencia y permita la armonía de las pasiones, a través del dominio de la voluntad.

\section{LA EDUCACIÓN DE LA PERSONA HUMANA}

La persona se manifiesta en las operaciones que van conformando su conducta. Estas operaciones, para ser típicamente humanas, deben tener un porqué y un para qué. Es entonces cuando aparece la dimensión ética del quehacer humano. "Las intenciones y los motivos son una dimensión de la acción humana y, por tanto, son temas morales: la intención es recta o no lo es, y de esta diferencia somos conscientes, por lo común". ${ }^{10}$

El hombre actúa bien en la medida en que despliega sus potencias en un proceso de perfeccionamiento mediante la realización de roles para los que tiene aptitudes. De esta forma, logra la plenitud de su naturaleza a través de una respuesta personal frente a la propia posibilidad de mejora, que pone en acto y subraya la condición única e irrepetible de su ser singular.

Cada uno al recibir la naturaleza humana recibe también un modo de realizarla, una vocación, un llamado, al que libremente hay que responder. Aunque se tienda a la felicidad por la realización de las propias posibilidades de perfeccionamiento, esa tendencia puede frustrarse porque existe la posibilidad de errar. 
En el ámbito de la inteligencia, el error puede provenir de la ignorancia, que supone una deficiencia en el conocimiento intelectual; o de la equivocación, por un inadecuado proceso del ejercicio racional. En el ámbito de la voluntad, se puede errar por una elección de lo indebido, si la voluntad se independiza de la recta razón.

También puede haber error porque se adormece la vida espiritual y se extrema la vida sensitiva; de esta manera se produce una actuación instintiva y pasional. De aquí la imperiosa necesidad de la educación para favorecer la armonía psíquica y el desarrollo integral de las potencialidades de la persona.

En su labor personalizada de educación, el pedagogo ha de investigar cómo se actualiza el proceso cognitivo en el nivel sensible y en el espiritual. Por ejemplo, si una persona se deja llevar excesivamente por la imaginación y rezaga la inteligencia, necesitará ayuda para equilibrarse y mejorar lo racional, de lo contrario, corre el riesgo de vivir en un mundo fantástico. Algo semejante puede suceder en el ámbito apetitivo, a veces se impone la vida pasional sobre la volitiva y también sobre la intelectiva. Cuando el ser humano es dominado por una pasión, puede llegar, en casos extremos a conductas irracionales: ira exacerbada, celos desmedidos, etcétera. Esto hay que corregirlo.

Lo importante es solucionar los problemas en el ámbito correspondiente, pero en interacción con todos los demás ámbitos. Si se trata de la afectividad, no se obtienen buenos resultados con argumentos intelectuales que resultan muy fríos. Primero habrá que satisfacer las necesidades afectivas y luego razonar. Sin embargo, si el educador se instala de manera permanente en el terreno afectivo, puede llegar a manipular o a ser manipulado. Con esto claudicaría de la función orientadora propia de su actividad profesional, al crear dependencias enfermizas, infantilismos, o resignaciones estériles que impiden el crecimiento personal. 
En toda práctica educativa se pueden considerar dos aspectos: el primero se refiere a la ayuda a los semejantes a través de actos de socialización que surgen por la relación educandoeducador. El segundo es un proceso de autosuperación en el que uno mismo desarrolla la propia singularidad.

Estas ideas se observan gráficamente en el esquema número 2. En él se habla de tres dimensiones humanas: la ontológica, la psicológica y la ética.

La dimensión ontológica señala que en el ser humano hay desde el momento de su concepción - una naturaleza propia de su especie que en cada caso tiene una existencia singular e irrepetible. Esta naturaleza comprende los valores humanos y toda la potencialidad que se desplegará en la vida de relación, sobre todo a través del proceso educativo, que es una forma de concretar la sociabilidad.

Pero el desarrollo integral de la persona humana debe comprender también las dimensiones psicológica y ética, respectivamente.

La dimensión psicológica supone la realización de las potencias humanas de un modo individual, para adquirir una personalidad que distingue a cada cual. La dimensión ética se refiere al nivel de perfección que se alcanza responsablemente, gracias al buen uso de la libertad. Por esta razón, sólo tiene carácter quien posee virtudes.

Esto significa que una persona se distingue de otra por las variadas manifestaciones de su personalidad, por sus gustos, sus intereses, su manera de expresarse, de enfocar los problemas, etcétera. Pero sólo será una persona virtuosa y tendrá carácter si su personalidad y su conducta están de acuerdo con la dimensión ética, elegida libre y responsablemente.

Por tanto, la tarea educativa consistirá en integrar los dos ámbitos de desarrollo humano -psicológico y ético- para que la personalidad y el carácter se concreten en una unidad de vida. 


\section{CONCLUSIONES SOBRE EL QUEHACER DEL PEDAGOGO}

El verdadero conocimiento de la naturaleza del hombre hará posible la auténtica educación integral y así:

* Será realista porque partirá de la naturaleza tal cual es.

* Logrará impulsar la mejora de cada persona a partir de sus posibilidades reales.

* Identificará el ámbito de los problemas para resolverlos in situ, sin descuidar la integralidad de la persona.

* Promoverá la rectitud en la elección de medios y fines, y la constancia en la ejecución.

* Propiciará la estabilidad del nivel afectivo.

* Impulsará el crecimiento personal y la responsabilidad social.

El educador, como causa eficiente de la educación, deberá tomar en cuenta:

* El ámbito de receptividad de cada educando, porque todo ser humano tiene en su naturaleza el principio pasivo.

* La capacidad de actuar y de influir en otros, para impulsar el principio activo de los educandos.

* La necesidad de ser realista con lo que pide a sus educandos, en el binomio dar-recibir, porque está ubicado dentro del campo de las operaciones humanas.

* La finalidad de las actividades humanas que deben encaminarse hacia el bien ser y el bien hacer -propio de la virtudambos fuente de bienestar.

* El autoconocimiento de las propias aptitudes para ponerlas al servicio de la tarea educativa.

* La labor de investigación de nuevos métodos de enseñanza, de la oportunidad para aplicarlos y de la evaluación de los resultados.

El desconocimiento de la naturaleza humana propicia reduccionismos en el concepto de hombre, y por tanto, parcialidad en la educación, con todas sus gravísimas consecuencias. 
Las distintas vías de educación -por ejemplo, la capacitación, deben propiciar la mejora en todos los ámbitos de la persona.

\section{GLOSARIO}

- Afectividad: Diversidad de actitudes que manifiestan el cariño.

- Afectos: Estado emotivo que facilita la espontaneidad de las reacciones.

- Apetitos: Tendencias que mueven a conseguir algo.

- Causa eficiente: Es de quien fluye una acción que hace que algo sea, o sea de algún modo.

- Causa formal: Es el paradigma que determina intrínsecamente al sujeto.

- Causa final: Aquello para lo cual algo se hace.

- Causa material: Aquello en lo que y desde lo que algo se hace.

- Devenir: Movimiento, cambio, proceso.

- Esencia: Señala el modo de ser de los sujetos.

- Ética: Ciencia filosófica que estudia la moralidad de los actos humanos.

- Ético: Perteneciente a la bondad o maldad de los actos humanos.

- Espiritual: Perteneciente al ser independiente de la materia.

- Libertad: Autodeterminación al bien debido.

- Neurofisiológico: Relación de la estructura nerviosa con las funciones.

- Ontológico: Perteneciente al ser en sí mismo.

- Principio activo: Punto de partida de la influencia de un ser sobre otro.

- Principio pasivo: Punto de apoyo para recibir la influencia de otros.

- Psicológico: Perteneciente a los fenómenos vitales: conducta y procesos mentales.

- Sensitivo: Perteneciente a los sentidos corporales.

- Ser: Primera perfección que coloca a las criaturas en la realidad, junto con la esencia.

- Sustrato: Lo que se considera soporte, sustento o fondo.

- Vida psíquica: Aspectos vitales que surgen de un dinamismo interior específico.

\section{REFERENCIAS BIBLIOGRÁFICAS:}

${ }^{1}$ Cfr. GARCÍA HOZ, Víctor. Principios de Pedagogía sistemática, p. 25.

${ }^{2}$ Cfr. GRAN ENCICLOPEDIA RIALP, voz NATURALEZA, tomo 16, p. 604.

${ }^{3}$ El calificativo perfección lo entendemos como lo que actualiza bien la propia naturaleza, porque directamente siempre es un beneficio para la persona, e indirectamente para los demás. 
${ }^{4}$ Cfr. YEPES Stork, Ricardo. Fundamentos de antropología, p. 97.

${ }^{5}$ POLO, Leonardo, Quién es el hombre , p. 212.

${ }^{6}$ El alma de los animales y vegetales está sustentada en lo material, por eso, cuando lo material se descompone arrastra al alma correspondiente.

${ }^{7}$ Cfr. CHOZA, Jacinto. Manual de Antropología filosófica, p. 405.

${ }^{8}$ Cfr. GRAN ENCICLOPEDIA RIALP, voz POTENCIA, tomo 19, p. 2.

${ }^{9}$ Cfr. DICCIONARIO DE LAS CIENCIAS DE LA EDUCACIÓN, voz: AFECTIVIDAD, volumen I, p. 56.

${ }^{10}$ POLO, Leonardo, Ética: hacia una versión moderna de los temas clásicos, p. 215 .

${ }^{11}$ Cfr. LÓPEZ DE LLERGO, Ana Teresa. Naturaleza humana y educación, p. 11.

${ }^{12}$ Cfr. LÓPEZ DE LLERGO, A. Op. cit., p. 12

\section{BIBLIOGRAFÍA:}

CHOZA, Jacinto. Manual de Antropología filosófica, Rialp, Madrid, 1988.

DICCIONARIO DE LAS CIENCIAS DE LA EDUCACIÓN, $1^{\text {a }}$. reimpresión, volumen I, México 1993.

GARCÍA HOZ, Víctor. Principios de Pedagogía sistemática, Rialp, Madrid, 1960. GRAN ENCICLOPEDIA RIALP, $6^{\mathbf{a}}$ edición, Madrid 1989, tomos XVI y XIX. LÓPEZ DE LLERGO, Ana Teresa. Naturaleza humana y educación. FUNDICE, México 1994.

POLO, Leonardo:

Ética: hacia una versión moderna de los temas clásicos, Universidad Panamericana, 1993.

Quién es el hombre, Rialp, 1991.

YEPES Stork, Ricardo. Fundamentos de antropología, EUNSA, Pamplona, 1996 
ESQUEMA NO. 1: LOS ÁMBITOS HUMANOS ${ }^{11}$

\begin{tabular}{|c|c|c|}
\hline ÁMBITOS & SENSITIVO & ESPIRITUAL \\
\hline Cognitivo & $\begin{array}{l}\text { Sentidos: } \\
\text {-Externos (5) } \\
\text { - Internos } \\
\text {. Sentido común } \\
\text {. Imaginación } \\
\text {. Cogitativa } \\
\text {. Memoria }\end{array}$ & $\begin{array}{l}\text { Inteligencia } \\
\text { (verdad) }\end{array}$ \\
\hline Apetitivo & $\begin{array}{l}\text { Pasiones } \\
\text { - Concupiscibles } \\
\text { Amor - odio } \\
\text { Deseo - aversión } \\
\text { Gozo - tristeza } \\
\text { - Irascibles } \\
\text { Esperanza - } \\
\text { desesperanza } \\
\text { Audacia - temor } \\
\text { Ira }\end{array}$ & $\begin{array}{l}\text { Voluntad } \\
\text { (bien) }\end{array}$ \\
\hline
\end{tabular}




\section{ESQUEMA NO. 2: DIMENSIONES HUMANAS ${ }^{12}$}

\begin{tabular}{|c|}
\hline PERSONA HUMANA \\
Dimensión ontológica \\
Naturaleza humana: \\
$*$ individualidad \\
$*$ irrepetibilidad
\end{tabular}

Valores

EDUCACIÓN

Sociabilidad
EDUCACIÓN

Sociabilidad

\begin{tabular}{|l|}
\hline PERSONALIDAD \\
Dimensión psicológica \\
Despliegue de la natu- \\
raleza por medio de las \\
características persona- \\
les
\end{tabular}

Distinción
CARÁCTER

Dimensión ética

EDUCACIÓN

Sociabilidad

Concreta la responsabilidad de llegar a la perfección propia

Virtudes 